\title{
AIDS myths that need eradicating
}

As emerged vividly at this year's international AIDS conference, prospects have never been so bright for new therapies. But some tales are spreading that are fictitious.

SCIENTISTS, activists and even journalists at the eleventh international conference on AIDS in Vancouver, Canada, earlier this month (see Nature 382, 101; 1996) spent much of their energy trying to ensure that the progress made so far in fighting the disease is kept in perspective. Initially, their effort paid off and most of the tidal wave of media coverage from the meeting was reasonable and fair. But as time passes, memories of that perspective fade, and some outlandish versions of events are gaining currency. There are several myths that need to be repudiated.

The largest states that combination drug therapies now under small-scale trial can be regarded as a likely 'cure' for HIV disease. The 'c' word was assiduously avoided by drug company scientists and other experts at Vancouver, but its misuse persists.

The trials undertaken so far of various promising combinations of protease inhibitors and other therapies are too small and too idealized to assure that the treatments will permanently reduce viral load. Even if they do, there is no evidence (or likelihood) that they will eradicate the virus from the body; the chances are that it will remain in the lymph nodes and in the central nervous system, requiring indefinite treatment with powerful drugs whose long term health effects are unlikely to be entirely benign. The success of the combination therapies in early trials is an encouraging sign on an otherwise bleak landscape; it is not a cure.

An opposite misconception of the combination therapies holds that they constitute little more than a plot by drug companies to extract money from the victims of the disease. The cost of the therapies - at $\$ 6,000$ or more a year for each component of the threeway combinations - is seen by many as not just unaffordable, but morally offensive. Larry Kramer, the respected AIDS activist, recently attacked the pricing in the New York Times, calling for "a programme to coordinate research, contain drug company greed and insure us all adequately".

An argument can certainly be made that capitalism is morally bankrupt. But it is profit-driven competition between corporations that has led to the protease inhibitors that now bring AIDS sufferers some hope. The divisions of those corporations that are engaged in pertinent research need revenue now, in order to win resources from inside the corporations for the further research which will duly yield better drugs. This mechanism may lack a moral dimension - but no known alternative model will yield better results.

The third myth surrounding the combinations is that they will chiefly serve to mutate the virus into new, and even more drugresistant forms. But the single most promising aspect of the combinations is their apparent ability to restrict the number of mutations sufficiently to prevent this from occurring. The argument that diseases should not be fought because they then become more resistant is an argument for the cessation of all research into their cause and treatment.

A fourth myth contends that the character of the AIDS research community has undergone a fundamental change in the last two or three years, spawning new promise in the field. That fairy tale holds that a new, non-territorial, non-combative class of AIDS researcher has emerged, motivated only by the greater good, and free from the factionalism which supposedly consumed the 'old guard' after they began the war against the disease a dozen years ago.

The US research effort may have shifted from the laboratories of the National Institutes of Health to new, extramural teams. But the 'new guard' has its factions and its egos too, and the old guard deserves some respect. Attempts by the new generation to contrast itself with the last one suggest a dangerous degree of self-delusion.

The final Vancouver myth holds that the arrival of effective drug therapies for use in the developed world will destroy the prospects for an effective vaccine for the developing world, where nine-tenths of new HIV infections now arise. That could happen if such drug treatments become available, but it need not. The community has been warned of the danger, and must act accordingly.

Ultimately, the virus will only be eradicated by a vaccine. Several initiatives are now under way to clear obstacles which lie in the path of vaccine development. Researchers and research funding institutions in every part of the world must ensure that this goal is kept firmly in mind.

\section{German lessons}

The German government is to reduce its contribution to European laboratories. Scientists need to be realistic.

GERMANY's tough squeeze on public spending announced earlier this month (see Nature 382, 196; 1996) implied cutbacks in support for applied research programmes, non-renewal of some research projects, and protection in general for basic science. But a third strand has now come to light: cuts averaging 6 per cent are to be imposed on German contributions to five major European research institutions (see page 285). These include the European Laboratory for Molecular Biology, the European Synchrotron Radiation Facility, and - perhaps most prominently given the current delicate state of negotiations over the Large Hadron Collider - the European Laboratory for Particle Physics (CERN).

The cuts will come as little surprise to close followers of European science policy. Evidence has been growing in recent years that the country's previous willingness to help pay for large scientific projects can no longer be taken for granted. But the new proposals will still come as a shock to the many scientists they will inevitably affect. Although the cuts have still to be formally approved by the Bundesrat, Germany's higher legislative body, that looks unlikely to represent a major hurdle.

Two conclusions can be drawn. The scientific community will be deluding itself if it fails to accept that the shift in Germany's thinking is part of an unstoppable trend that is part of the uncomfortable political and economic reality of the late 1990s. Second, all preconceptions need a critical reappraisal. For example, just how European does CERN have to be? Only after such questioning and some imaginative thinking will it be possible to negotiate structural adaptations that best protect the long-term interests of basic research. And only then will it be sensible and possible to correct the imbalance in commitments to national and international expenditures on basic science that many industrialized countries, not just in Europe, are now facing. 